\title{
Chapter 11 \\ Reversed Mobilities as a Means to Combat \\ Older People's Exclusion from Services: \\ Insights from Two Alpine Territories \\ in France and Italy
}

\author{
Florent Cholat and Luca Daconto
}

\subsection{Introduction}

(Im)mobility and (in)accessibility play a key role in older people's exclusion from services. It can particularly happen in mountain areas, where we can find lower availability of services and higher transport constraints (slope gradients; lack of public transportation; weather conditions, etc.). Consequently, movement is necessary to reach and engage in relevant services. Older people's ability to move, the so-called motility or capital of mobility (Kaufmann et al. 2004), plays an important role in combatting exclusion from services, and social exclusion in general. It allows access to opportunities at specific locations, through which desires can be fulfilled, needs satisfied, and social networks maintained. While older people with a high capacity for mobility might easily adapt to the "mountain", accessing these opportunities is much more difficult for individuals with lower motility, such as frail and vulnerable older adults (Lord 2011), who may not be able to participate in relevant services (Church et al. 2000; Kenyon et al. 2002; Lucas 2012). In order to cope with the risks of spatial- and mobility-related exclusion from services, and social relations, people with a low capacity for mobility require and engage in a set of reversed mobilities (Cholat 2013). Reversed mobilities can be defined as different forms of indirect accessibility (Hine and Grieco 2003; Kellerman 2012) to relevant services based on the mobility of others, such as relatives, caregivers, social and health workers and mobile retailers.

\footnotetext{
F. Cholat $(\triangle)$

LabEx ITTEM, University Grenoble Alps, Gières, France

University of Milan Bicocca, Milan, Italy

e-mail: florent.cholat@univ-grenoble-alpes.fr

\section{Daconto $(\bowtie)$}

Department of Sociology and Social Research, University of Milan Bicocca, Milan, Italy

e-mail: luca.daconta@unimib.it
} 
This adaptive strategy responds to a form of exclusion from services that is constituted across and impacts different spheres (spatial, transport, services and social relations) due to the interaction between environmental and individual level vulnerabilities. While reversed mobilities potentially represent a very important means of combatting older people's exclusion in mountain areas (Cholat 2013, 2018; Cholat et al. 2017), they may also shape and create further inequalities and compound exclusion for some individuals who do not have at their disposal the financial and relational resources needed to activate these strategies.

This chapter aims to stress how reversed mobilities may contribute to a better understanding of exclusion from services. In particular, we will analyze (1) the interaction between different factors in constructing service inaccessibility as an exclusionary process in the lives of mountain dwelling older people; (2) the key role played by reversed mobilities in combatting older people's experience of exclusion from services in mountain areas, as well as the environmental, economic and social costs and "new" inequalities that might be associated with this form of adaptation. As such, our analysis will address both exclusion from transport services, and exclusion from general services, and how these exclusions intersect, and how their impact are accentuated as a result of individual and environmental vulnerabilities.

Despite the potential role that reversed mobilities could play in combatting older people's social exclusion and guaranteeing the vitality of mountain areas, the topic has not been sufficiently considered by research, planning and public policy. This has consequences for our capacity to make informed decisions about the way to effectively support older people and promote their inclusion in these contexts.

To deepen our understanding of reversed mobilities, we will review the international literature on this topic, and draw on an exploratory analysis carried out in two European Alpine territories (Isère, France and Bergamo, Italy) to illustrate where such reversed mobilities may be needed and may be occurring. First, we review from a theoretical perspective the ways the relationship between older people and mountain environments may influence (in)accessibility to opportunities and lead to mutually reinforcing exclusionary processes. Next, we will explore the key role played by reversed mobilities in countering older people's exclusion from different domains in mountain areas and highlight challenges regarding the sustainability and inequalities of this form of adaptation. In conclusion, we will discuss the extent reversed forms of mobility offer a strategy for other socio-cultural environments in promoting older people's inclusion. We will also highlight some key research/policy gaps and required future directions. 


\section{2 (Im)Mobility and Service (in)Accessibility Related to Older Adults' Social Exclusion}

Mobility is a very important dimension of well-being in later life (Metz 2000; Banister and Bowling 2004). Indeed, as for other groups, mobility is a facilitator of well-being and inclusion, as it allows older people to have access to opportunities and to participate in relevant services at specific locations. In addition, mobility is not just a means for participating in societies (as in the case of accessibility), but it is also an end in itself (Urry 2007). It can promote well-being directly such as in the form of: happiness and pleasure, felt during a trip with relevant others (e.g. relatives, grandchild, friends, neighbours) in an attractive environment (e.g. familiar places); and physical activity, as an active mobility central to healthy ageing (Swedish National Institute of Public 2007).

Despite the benefits of mobility in later life, studies (e.g. Colleoni 2016) generally show a lower likelihood among older people to be mobile, whatever the specific modal solution considered, compared to other social groups. ${ }^{1}$ Generally, gerontological mobility research (OECD 2001; Risser et al. 2010; Nordbakke 2013) points out existing barriers to transport mobility in old-age (e.g. diseases or personal mobility difficulties; environmental barriers; physical obstacles; design/structure of public transport; lack of safety; accidents). However, more recent studies suggest the need to go beyond a simple transportation perspective of older adult mobility and to put more emphasis on emotional, motivational and social aspects of being mobile (Kaiser 2009; Lord et al. 2011). In this sense, Kaufmann et al. (2004) has introduced the concept of motility, and define it as the set of characteristics that enable people to move, i.e. a property of individuals shaped by biological, psychophysical, socio-cultural and environmental factors (De Witte et al. 2013).

Indeed, if older people's low motility is due to obstacles associated with agerelated psychophysical health (Henrard 2007), a relevant role is also played by the relationship between this individual vulnerability and the characteristics of the environment. In these cases, the environment can act as a further determinant, able to enhance or limit individual functional ability. That is, the particular features of the built and social environment can improve or restrict personal capabilities, as conceived in the capability approach by Sen (1993) [see Tournier and Vidovićová, and Drilling et al. this volume for a discussion about older people's interactions with these aspects of the environment].

In this sense, mountain areas may further constrain older people's ability to move, as they are partly characterised by low availability of general services, lack of transportation and geographical and physical barriers (e.g. slope, road closures, seasonal

\footnotetext{
${ }^{1}$ However, senior mobility demand is highly differentiated. For instance, young older adults (65-74 years) have a profile very similar to that of the general adult population as regards the number of journeys and the high use of the car. The use of the car collapses in the older-age groups, unlike walking, which is the older people's privileged modal choice, in particular for women and those aged 75 years or more.
} 
and weather conditions, etc.). In order to access opportunities and to participate in services relevant for social inclusion not available at the local scale (such as working, accessing goods and services, and maintaining social networks), the older mountaineers must be able to move and overcome the "mountain" constraints.

Consequently, the intersection between individual (low motility) and environmental (low transport and accessibility) vulnerabilities can result in limited accessibility to opportunities (Dijst and Kwan 2005) - not only goods, facilities and services but also the whole set of services which allow individuals to satisfy both elementary and more complex needs related to identity, relationships and social participation. Such limitations have been recognised as undermining older people's quality of life and potentially leading to their exclusion from different domains (SEU 2003) [also see Tournier and Lucie Vidovićová this volume for the discussion of person-environment fit as a relevant concept to this interaction of individual and environmental characteristics]. From this perspective, accessibility - described as "the ability of people to reach or take part in services or opportunities" (Farrington 2007 p. 321) - represents a condition necessary to exercise full citizenship (Madanipour et al. 1998) and so becomes a social indicator (Geurs and van Wee 2004) that is able to shed light on the ways to achieve social justice and inclusion (Martens 2016). For instance, it shows the mutually reinforcing exclusionary processes that may affect older people living in mountain areas resulting from the intersection of spatial, service, transport and individual dimensions. Furthermore, the notion of accessibility can help orient policy intervention towards more appropriate areas and populations.

In the context of "mountain" constraints, it is possible to observe new forms of inequalities linked to older people's different levels of motility. On the one hand, an older person with greater motility can respond to inaccessibility by choosing a mode of travel more suited to their needs, attitudes and preferences. On the other hand, transport poverty (Lucas et al. 2016), and lack of choice, and low capacity for mobility can lead to social exclusion and isolation. The intersection between environmental and individual vulnerability generates a circular set of dynamics: the low availability of services requires older people's mobility; high physical and transport barriers and low individual capacity for mobility lead to immobility and inaccessibility to relevant opportunities, which, in turn, bring an increased vulnerability to exclusion from services.

However, some scholars warn against this interpretation, which does not consider the vulnerable groups' expedients (Belton Chevallier et al. 2018) or coping strategies (Jouffe et al. 2015) in order to move, and access relevant opportunities. It is in this light, that these groups may turn to a set of reversed mobilities (Cholat et al. 2017), at least indirectly (Hine and Grieco 2003; Kellerman 2012) delivered by services or support networks (family, neighbours, etc.), to ameliorate risks of isolation and exclusion. For example, the weak motility of an older person may be compensated by the mobility of other people (professionals, family carers, neighbours or friends) that can meet his/her daily needs: if the older person no longer moves the goods and services will have to go to him/her. It is these reversed mobilities that we now consider. 


\subsection{Reversed Mobilities in Mountains: Types and Evidence}

After outlining what reversed mobilities respond to and where they may be needed, in this section we propose a classification (Table 11.1) for the purpose of describing their actual use in the mountain regions of Isère (France) and Bergamo (Italy) based on previous work (Cholat 2013; Cholat et al. 2017). Reversed mobilities differ primarily in their purpose. For ageing mountain dwelling populations, these purposes focus primarily on ageing in place and mainly concern accessing health care and the main activities of daily living, such as shopping, socialisation and home maintenance/delivery services. Reversed mobilities therefore also vary according to the type of actor who moves. It is possible to distinguish at least three primary sources of reversed mobilities: family and local communities; public welfare institutions; and private sector companies.

Considering the healthcare purpose, a significant source of reversed mobilities in mountain areas is the Socio-Medical Home Assistance service provided by state institutions. For instance, in Bergamo, the proportion of older users of the Home Assistance service is greater in mountain areas, as is the per-capita expenditure for the delivery of meals, home laundry and social transport. ${ }^{2}$ Access to goods and services is guaranteed by different actors. In a previous study (Cholat 2013; Cholat et al. 2017), conducted in these two mountain communities (Entraigues, Isère, France; Isola di Fronda, Bergamo, Italy), the private sector (e.g. mobile shops and home delivery) emerged as a main source of reversed mobilities, since family, relatives and friends live relatively close by in these areas. Considering dependent older adults, reversed mobilities constitute on average a distance of $293 \mathrm{Km}$ per week in Isère and $121 \mathrm{Km}$ per week in Bergamo. In Italy, territorial welfare policies aim to manage and harness reversed mobilities through the activation of the so-called Community "Butler" service, a figure who performs various services (e.g.

Table 11.1 Reversed mobilities: A classification of type and provider

\begin{tabular}{l|l|l|l}
\hline & $\begin{array}{l}\text { Family and local } \\
\text { community }\end{array}$ & Public welfare & Private sector \\
\hline \multirow{2}{*}{$\begin{array}{l}\text { Healthcare and home } \\
\text { maintenance }\end{array}$} & - Support & $\begin{array}{l}\text { - Socio-Medical Home } \\
\text { Assistance }\end{array}$ & $\begin{array}{l}\text { - "Badante"/ } \\
\text { Caregiver }\end{array}$ \\
\cline { 2 - 4 } & $\begin{array}{l}\text {-Socialisation and } \\
\text { social care }\end{array}$ & - Personal assistance & \\
\hline \multirow{2}{*}{ Goods } & - Shopping & - Meal delivery & - Mobile shops \\
\cline { 3 - 4 } & $\begin{array}{l}\text { - Laundry service } \\
\text { delivery }\end{array}$ & - Home delivery \\
\hline Services & - Running errands & - Social Transport & - Mobile shops \\
\cline { 3 - 4 } & - Community "Bulter" & - Home delivery \\
\hline
\end{tabular}

\footnotetext{
${ }^{2}$ In 2014, the total management cost of public services was $€ 1,887,513$ in the mountain domains of Bergamo (Source: Regional Health Fund 2014).
} 
shopping; delivery; laundry; handling administrative paperwork; shipping and payment of utilities).

\subsection{Mountain Territories and Indirect Accessibility by Reversed Mobility}

The mountain is not a homogeneous territory and it is necessary to take into account the variation in the availability of services. This includes well-resourced and connected mountain settings, such as tourist zones and the "urban" and "metropolitan" mountain centralities, to more disconnected sites, such as remote villages and less desirable municipalities. The level of accessibility can also vary according to weather, seasons and climatic conditions (e.g. holiday/tourism period, snow cover, road closures, etc.). Furthermore, it is also necessary to consider the characteristics of the resident community (e.g. socio-economic conditions, identity and solidarity, share of frail/vulnerable population). Therefore, the intensity of reversed mobilities depends primarily on the "floating" availability and accessibility of sufficient goods and services at the local level. Then, the intensity of reversed mobilities is influenced by the older population's level of autonomy and motility. To illustrate these considerations in a very broad way, we draw on an empirical example from two mountainous regions.

\subsubsection{Illustrating the Need for Reversed Mobility in Ageing Mountain Dwelling Populations}

We analysed the spatial distribution of basic services and the older population ${ }^{3}$ in two European alpine regions: Départment de l'Isère, France and Provincia di Bergamo, Italy. These two territories, although each has a different geographic scale (Isère: 7431 Sq. Km, Bergamo: 2746 Sq. Km), are comparable in their territorial structures. From a geomorphological point of view, these two territories include both an agricultural plain, which lies north of Isere and south of the province of Bergamo, and a mountainous area close to important urban centres like the city of Grenoble (450,000 inhabitants) and the city of Bergamo (480,000 inhabitants). We use a geographic information system model (through a kernel density estimation (KDE- Daconto et al. 2017) to calculate and represent the percentage and spatial distribution of residents aged 75 years and over within the total municipal population, and to contrast this age structure concentration with the availability of basic

\footnotetext{
${ }^{3}$ The analysis of the resident population is based on open data provided by the national statistical agencies, namely INSEE for France via the 2016 population census and ISTAT for Italy via the 2011 census. In France, the data source is the SIRENE directory of INSEE (2017), while in Italy the same data are available via the 2011 census of industry and services (ISTAT). The collected data were inserted into a
} 
services across these two regions. Services included in the analysis were selected on the basis of those identified within the literature as being critical for daily life and older adult inclusion (Krizek et al. 2012). These included: health services (e.g. pharmacies, physicians; hospital services; primary and community care clinics), supermarkets and shops, and places of sociability (bars/cafés).

At a first level of analysis, and with reference to Figs. 11.1 and 11.2, it is possible to identify the areas most exposed to the need for reversed mobilities where a low availability of services combines with a higher presence of potentially dependent older people, e.g. residents aged 75 years and older. In analysing the spatial distribution of basic services and the older population it is possible to argue that the availability of services is greater in urban and tourist areas and in the mountain resorts (Figs. 11.1 and 11.2).

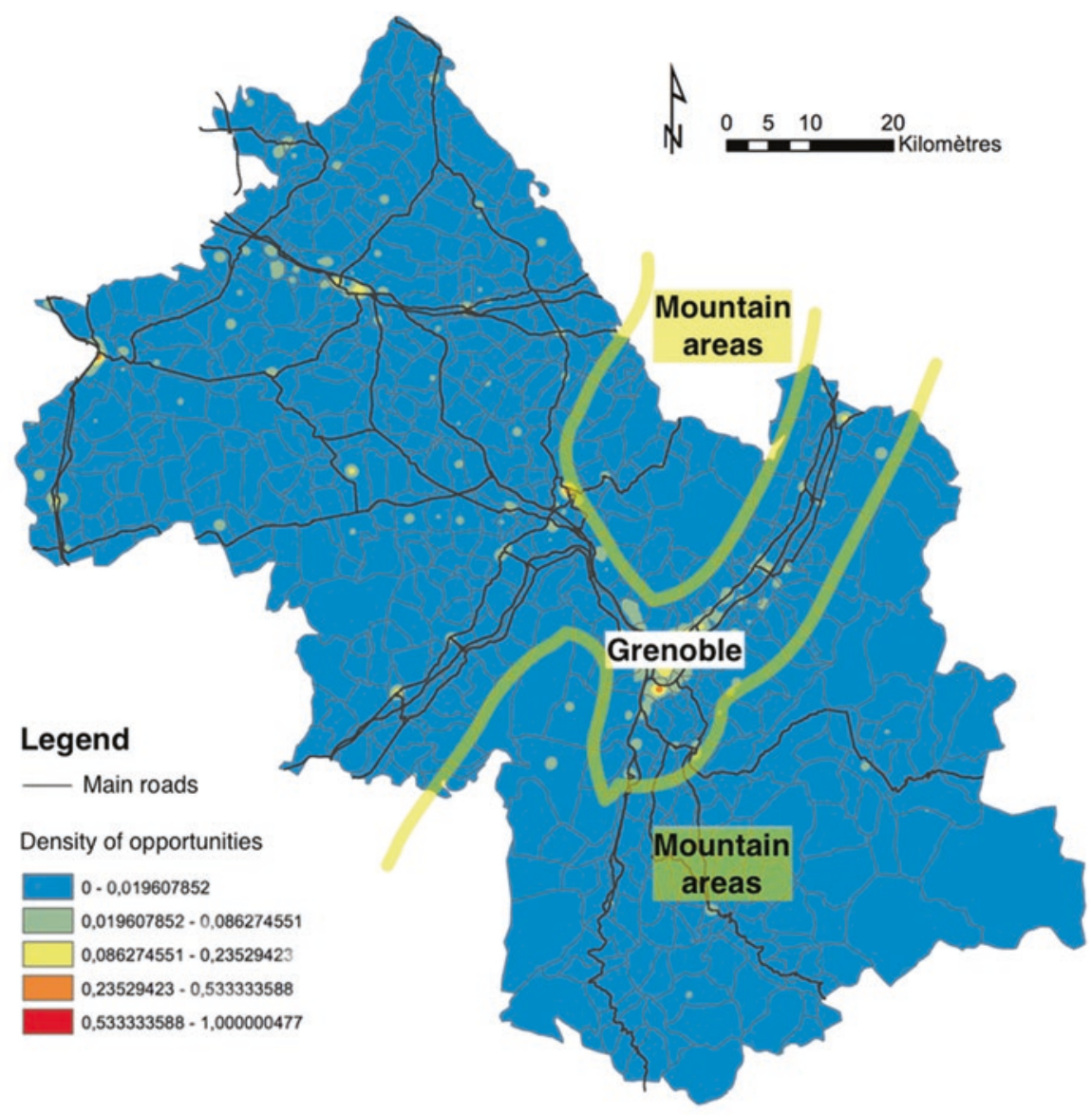

Fig. 11.1 The density of basic services in the department of Isère Source: authors' elaboration on data INSEE, 2017, IGN, 2016 


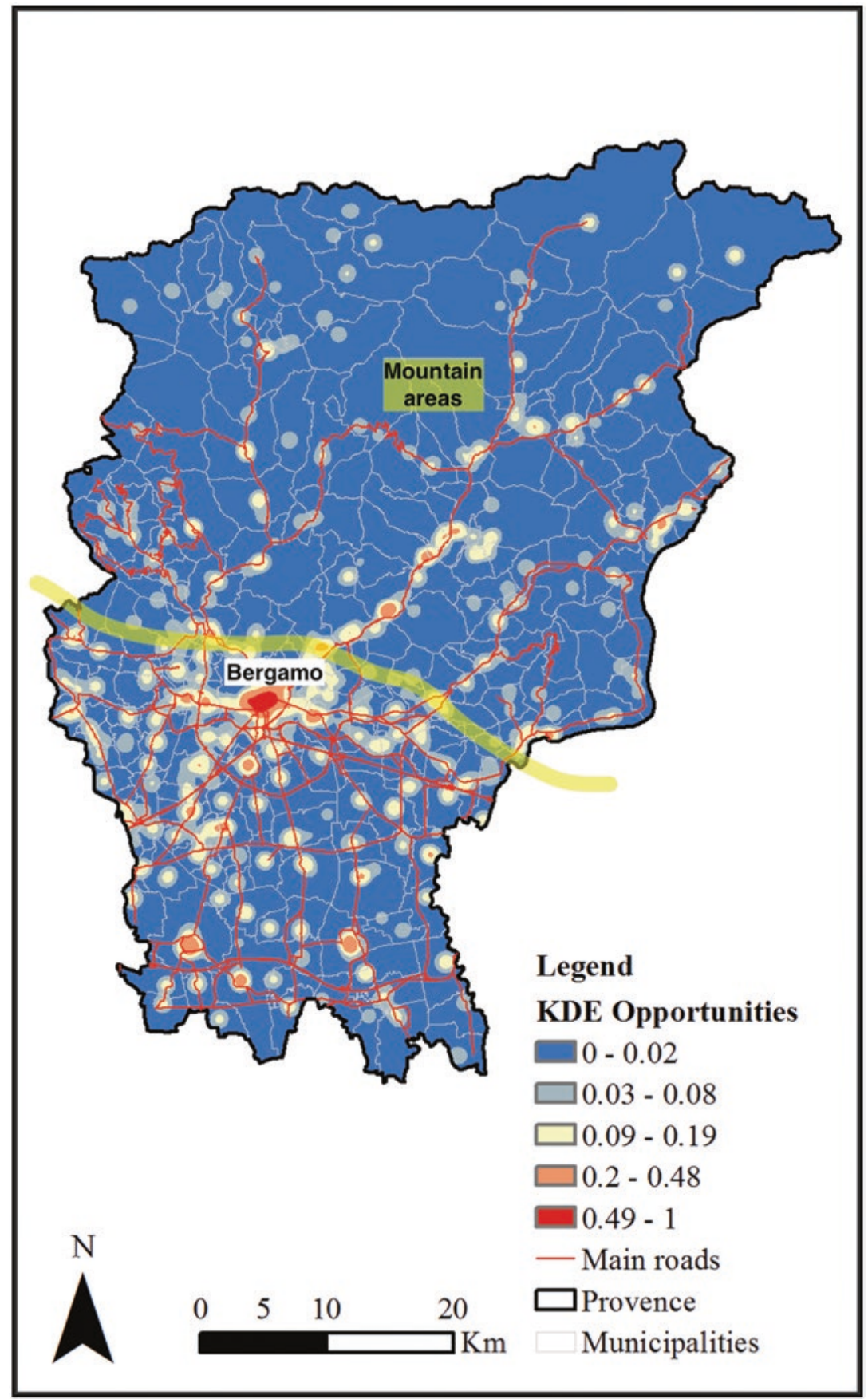

Fig. 11.2 The density of basic services in the province of Bergamo Source: authors' elaboration on data ISTAT, 2011, OSM, 2017 
Outside these areas, the availability of services, represented by a numeric scale, are lower, or even zero, in the non-peri-urban mountain. However, a higher offer of services in the mountain tourism areas is due to the seasonal presence (WinterSummer) of tourists and temporary residents. For instance, shops often suspend their activity outside the tourist seasons. This leads to a changing configuration of these territories in terms of the opportunities they offer and, consequently, in terms of their need for reversed mobilities. Following this temporal perspective, it is also possible to put forward the hypothesis that, thanks to a greater presence of primary roads, tourist areas are less sensitive to the seasonal variation in accessibility due to the climatic hazards (climate conditions, snow, storms, etc.) and the closing of roads. The proportion of 75-year-old residents within the total municipal population (Figs. 11.3 and 11.4) allows us to show an over-representation of older people in mountainous areas, in comparison with the urban, peri-urban and rural territories. In

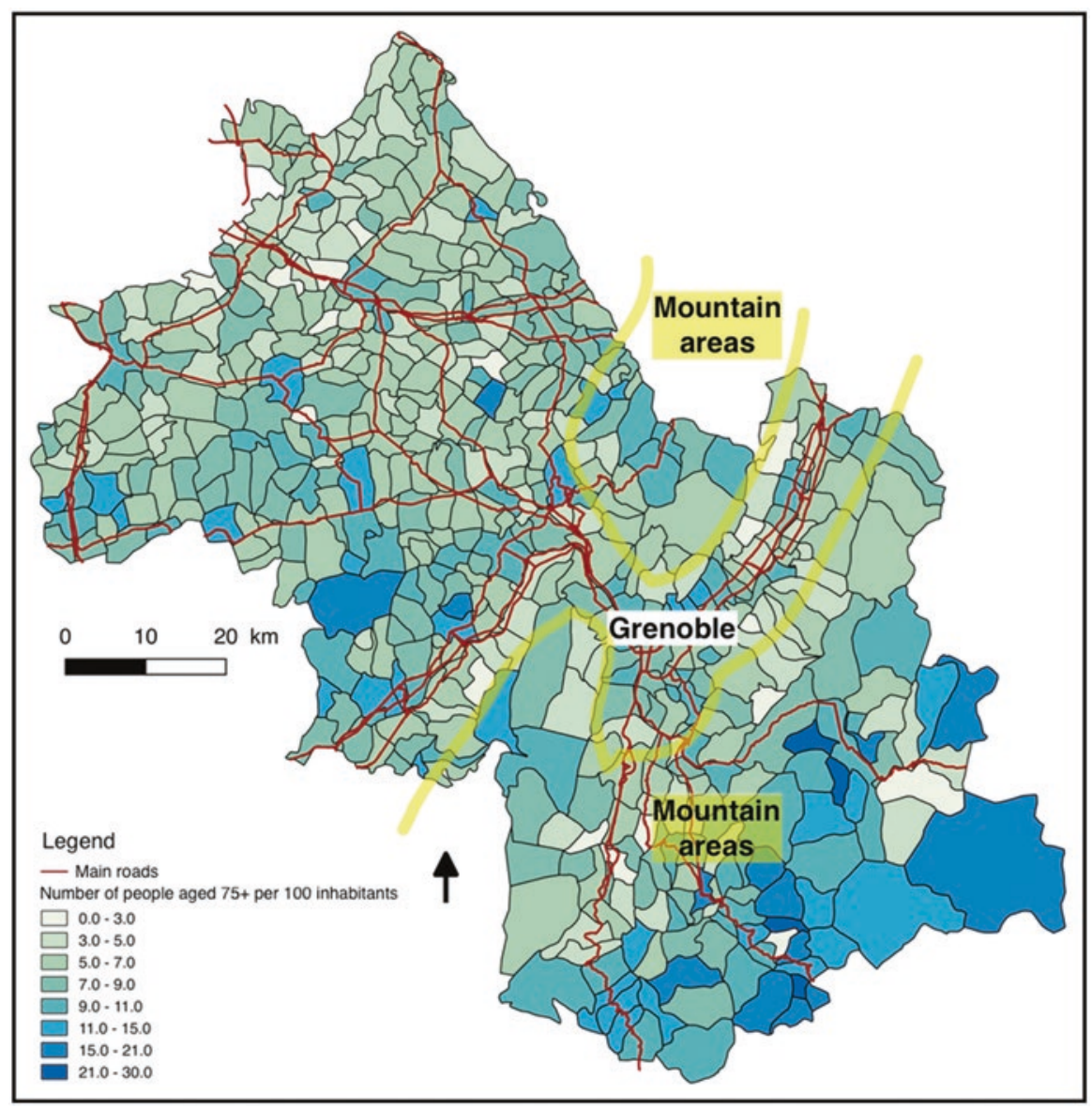

Fig. 11.3 Proportion of people aged 75 and over in the department of Isère Source: authors' elaborations on data INSEE, 2017, IGN, 2016 


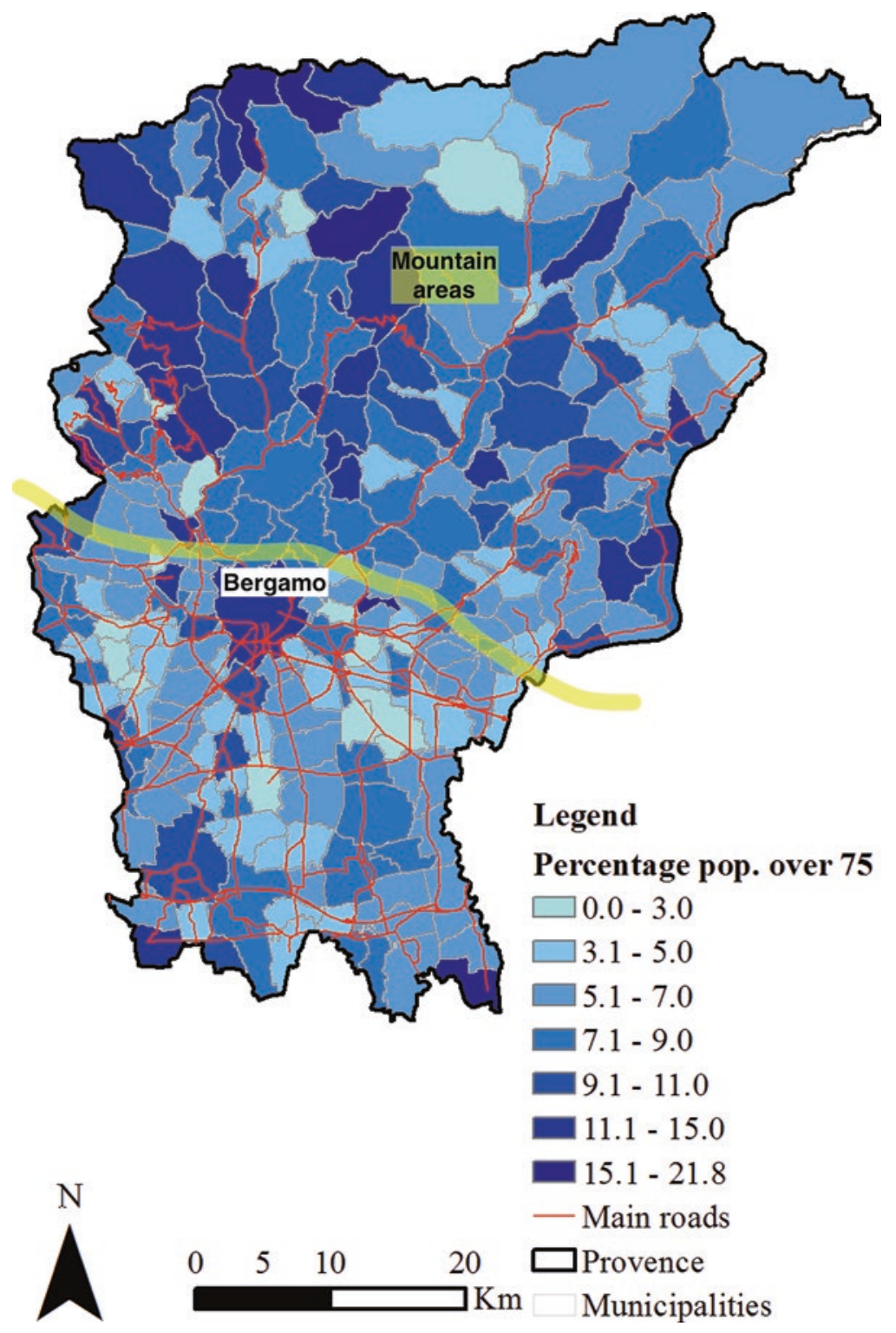

Fig. 11.4 Proportion of people aged 75 and over in the province of Bergamo Source: authors' elaboration on data ISTAT, 2011, OSM, 2017

this sense, mountain areas emerge as the territories most exposed to service exclusion.

In these types of contexts, where service, spatial and individual vulnerabilities overlap, reversed mobilities may represent an adaptive strategy in order to cope with environmental (low availability and accessibility of services) and individual (low 
ability to move) vulnerabilities. In this sense, they can be considered as a response to the overlapping mechanisms of exclusion that can arise from spatial, transport and individual dimensions which function to undermine older people's access to key spheres of activity (e.g. healthcare, welfare, social networks, shopping, etc.). Therefore, from an individual perspective reversed mobilities allow older people to combat or ameliorate multidimensional exclusionary processes and to participate in daily life. From a societal point of view, they contribute to the liveability (employment, residential economy, etc.) of the mountain (Smit and Wandel, 2006) ensuring the habitability of territories affected by processes of abandonment and depopulation strongly related to the lack and inaccessibility of services.

This response and adaptation is not universal, however, as reversed mobilities require financial, cultural and relational resources, which are necessary, for instance, to acquire private delivery services (e.g. commerce, caregiver, nurse, etc.), including online services (e.g. e-commerce), and to activate support networks (e.g. relatives, neighbours, etc.).

\subsubsection{Costs and Inequalities Related to Reversed Mobilities}

In terms of the increasing concerns surrounding the sustainability of these sorts of communities, reversed mobilities present environmental, social and economic costs that scholars, professionals and policymakers must consider. First, from an environmental point of view reversed mobilities are highly car dependent (Dupuy 1999) in the current model of territorial development. This significantly increases travel times and requires also the ability to overcome environmental barriers (e.g. slope, weather conditions, etc.) to access these mountainous regions. In a similar way, public transport is not sustainable without a critical mass of demand, an absence of which frequently characterises these mountain territories. Hence, reaching these destinations, by means of other modal choices than the car is more difficult in mountain areas. This implies that in order to access opportunities and to participate in services relevant for social inclusion, the mountaineers must move by car.

Second, reversed mobilities have an economic cost: the direct and indirect costs linked to the increased public expenditure to compensate for the negative externalities of motorised mobility and inactive lifestyles. For example, a previous research study conducted in the French-Italian Alps (Isère and Bergamo) has quantified the increased cost of reversed mobility related to serving ageing in place populations to be up to $€ 1800$ per settlement per week in France and $€ 800$ in Italy (Cholat 2013).

Third, there is a social cost. This refers to the inequalities in the capacity of older people to make use of this form of adaptation. Reversed mobilities can depend on the economic capital of the person and/or household (i.e. the financial resources necessary for paying private services, such as delivery and home services). Then, services provided by reversed mobilities depend on the different capacities of individuals to build, maintain and activate the network of resources and social ties in 
which individuals rely on to harness reverse mobilities (Fol 2009). As argued by Ohnmacht et al. (2009), this type of support is based on the mobilisation of strong ties within older people's local communities, because it is at this scale that contacts can be easily activated, if necessary. In this sense, it is important to distinguish a grouped vulnerability from a dispersed vulnerability (Hine and Grieco 2003). In the latter case, the dispersed nature of relationship networks may make it more difficult to obtain support (Shergold and Parkhurst 2012). In other words, local support can be what Retière (2003) defines as an autochthonous capital, which encompass all the resources that belong to a local network of relations, which can help people, especially the most vulnerable, to access opportunities (Fol 2010).

In this sense, reversed mobilities emerge not only as a means to cope with exclusionary processes, but may serve as a further marker of inequalities in themselves, where older individuals are unable to respond to environmental and individual vulnerabilities through this strategy, compounding the disadvantage experienced by older people.

\subsection{Conclusion}

Reversed mobility is a form of adaptation for people who have a low capacity for mobility, especially older adults living in contexts where services are lacking, and accessibility to services is more difficult (like some mountain areas). Since they ensure an indirect access to key opportunities, reversed mobilities are a strategy adopted by older people in order to cope with the risks of exclusion from services, and different spheres of life, due to the interaction between environmental (lack of services and accessibility) and individual (low ability to move) vulnerabilities. Thus, they can in some circumstances strongly contribute to older people's inclusion and the habitability of the territories.

Despite the key role played by reversed mobilities, the topic has not been sufficiently considered by research and policy. To fill this gap, this chapter has stressed how reversed mobilities may contribute to combating exclusion that derives from the interaction of different forms of vulnerability (spatial, transport, individual), potentially leading to mutually reinforcing processes of disadvantage. But while reversed mobilities may be an effective way to promote older people's inclusion, this type of response to exclusionary processes may create further inequalities due to the resources needed to activate them. Then, they have an environmental and economic cost that must be taken into account in a context where sustainability has become an imperative.

Our analysis of reversed mobilities allows for the identification of useful directions for future research and policy. First, since reversed mobilities represent a key element for older people's habitability in mountain contexts, the issue at stake for policymakers concerns their optimisation through planning, which can guarantee older people's inclusion and the sustainability of these territories. An important set of considerations therefore includes optimising travel, sharing mobility, the management of logistics, 
mitigating environmental impacts (e.g. vehicle efficiency) and the social inequalities related to the differential ability to make use of this form of adaptation.

Second, research can inform policies by identifying the areas potentially exposed to service exclusion as a result of individual and contextual vulnerabilities intertwining. This is possible by cross-referencing different indicators of accessibility and population (i.e. mobility, social, economic capitals). Once these areas are identified, it is then possible to develop further qualitative research to understand at a micro scale the mechanisms at work and the ways to actually support older people in these contexts.

\section{Editors' Postscript}

Please note, like other contributions to this book, this chapter was written before the COVID-19 pandemic of 2020. The book's introductory chapter (Chap. 1) and conclusion (Chap. 34) consider some of the key ways in which the pandemic relates to issues concerning social exclusion and ageing.

\section{References}

Banister, D., \& Bowling, A. (2004). Quality of life for the elderly: The transport dimension. Transport Policy, 11(2), 105-115. https://doi.org/10.1016/S0967-070X(03)00052-0.

Belton Chevallier, L., Motte-Baumvol, B., Fol, S., \& Jouffe, Y. (2018). Coping with the costs of car dependency: A system of expedients used by low-income households on the outskirts of Dijon and Paris. Transport Policy, 65, 79-88. https://doi.org/10.1016/j.tranpol.2017.06.006.

Cholat, F. (2013). Impact chrono-géographie de la perte d'autonomie liée à l'âgée, Master Thesis, Grenoble: University of Grenoble.

Cholat, F. (2018). Les «mobilités inversées» comme clé de lecture de la dépendance dans les territoires de montagne. Pour, 233(1), 97-101. https://doi.org/10.3917/pour.233.0097.

Cholat, F., Gwiazdzinski, L., \& Colleoni, M. (2017). Cartographier l'isolement. Une approche chronotopique de la vie quotidienne des personnes âgées. In G. Drevon, L. Gwiazdzinski, \& O. Klein (Eds.), Chronotopies. Lecture et écriture des mondes en mouvement (pp. 110-121). Grenoble: Elya Editions.

Church, A., Frost, M., \& Sullivan, K. (2000). Transport and social exclusion in London. Transport Policy, 7(3), 195-205. https://doi.org/10.1016/S0967-070X(00)00024-X.

Colleoni, M. (2016). La mobilità quotidiana delle popolazioni anziane. Salute e società, XV(1), 116-134. https://doi.org/10.3280/SES2016-001009.

Daconto, L., Colleoni, M., \& Gwiazdzinski, L. (2017). L'accessibilità spaziale potenziale alle opportunità urbane. Un'analisi comparata tra la città metropolitana di Milano e la metropoli di Lione. Archivio di studi urbani e regionali, XLVIII(119), 73-91. https://doi.org/10.3280/ ASUR2017-119005.

De Witte, A., Hollevoet, J., Dobruszkes, F., Hubert, M., \& Macharis, C. (2013). Linking modal choice to motility: A comprehensive review. Transportation Research Part A: Policy and Practice, 49, 329-341. https://doi.org/10.1016/j.tra.2013.01.009.

Dijst, M. J., \& Kwan, M. P. (2005). Accessibility and quality of life: Time-geographic perspectives. In K. Donaghy, S. Poppelreuter, \& G. Rudinger (Eds.), Social dimensions of sustainable transport: Transatlantic perspectives (pp. 109-126). Aldershot: Ashgate.

Dupuy, G. (1999). La dépendance automobile: Symptômes, analyses, diagnostic, traitements. Paris: Anthropos. 
Farrington, J. H. (2007). The new narrative of accessibility: Its potential contribution to discourses in (transport) geography. Journal of Transport Geography, 15(5), 319-330. https://doi. org/10.1016/j.jtrangeo.2006.11.007.

Fol, S. (2009). La mobilité des pauvres: pratiques d'habitants et politiques publiques. Paris: Belin.

Fol, S. (2010). Mobilité et ancrage dans le quartiers pauvres: les ressources de la proximité. Regards Sociologiques, 40, 27-43.

Geurs, K. T., \& van Wee, B. (2004). Accessibility evaluation of land-use and transport strategies: Review and research directions. Journal of Transport Geography, 12(2), 127-140. https://doi. org/10.1016/j.jtrangeo.2003.10.005.

Henrard, J.C. (2007). Les Défis du vieillissement. Paris: Découverte.

Hine, J., \& Grieco, M. (2003). Scatters and clusters in time and space: Implications for delivering integrated and inclusive transport. Transport Policy, 10(4), 299-306. https://doi.org/10.1016/ S0967-070X(03)00055-6.

Jouffe, Y., Caubel, D., Fol, S., \& Motte-Baumvol, B. (2015). Faire face aux inégalités de mobilité. Tactiques, stratégies et projets des ménages pauvres en périphérie parisienne. Cybergeo: European Journal of Geography. https://doi.org/10.4000/cybergeo.26697.

Kaiser, H. J. (2009). Mobility in old age: Beyond the transportation perspective. Journal of Applied Gerontology, 28(4), 411-418. https://doi.org/10.1177/0733464808329121.

Kaufmann, V., Bergman, M. M., \& Joye, D. (2004). Motility: Mobility as capital. International Journal of Urban and Regional Research, 28(4), 745-756. https://doi. org/10.1111/j.0309-1317.2004.00549.x.

Kellerman, A. (2012). Potential mobilities. Mobilities, 7(1), 171-183. https://doi.org/10.108 0/17450101.2012.631817.

Kenyon, S., Lyons, G., \& Rafferty, J. (2002). Transport and social exclusion: Investigating the possibility of promoting inclusion through virtual mobility. Journal of Transport Geography, 10(3), 207-219. https://doi.org/10.1016/S0966-6923(02)00012-1.

Krizek, K., Horning, J., \& El-Geneidy, A. (2012). Perceptions of accessibility to neighbourhood retail and other public services. In K. Geurs, K. Krizek, \& A. Reggiani (Eds.), Accessibility and transport planning: Challenges for Europe and North America (pp. 96-117). London: Edward Elgar.

Lord, S. (2011). Le choix de vieillir à domicile: l'inévitable adaptation des modes de vie. Évolution de la mobilité quotidienne d'un groupe d'aînés de banlieue pavillonnaire. Retraite et société, 60(1), 197-213.

Lord, S., Després, C., \& Ramadier, T. (2011). When mobility makes sense: A qualitative and longitudinal study of the daily mobility of the elderly. Journal of Environmental Psychology, 31(1), 52-61. https://doi.org/10.1016/j.jenvp.2010.02.007.

Lucas, K. (2012). Transport and social exclusion: Where are we now? Transport Policy, 20(0), 105-113. https://doi.org/10.1016/j.tranpol.2012.01.013.

Lucas, K., Mattioli, G., Verlinghieri, E., \& Guzman, A. (2016). Transport poverty and its adverse social consequences. Proceedings of the Institution of Civil Engineers - Transport, 169(6), 353-365. https://doi.org/10.1680/jtran.15.00073.

Madanipour, A., Cars, G., \& Allen, J. (1998). Social exclusion in European cities: Processes, experiences, and responses. London-Philadelphia: Jessica Kingsley Publishers.

Martens, K. (2016). Transport justice: designing fair transportation systems. New York-Abingdon: Routledge.

Metz, D. H. (2000). Mobility of older people and their quality of life. Transport Policy, 7(2), 149-152. https://doi.org/10.1016/S0967-070X(00)00004-4.

Nordbakke, S. (2013). Capabilities for mobility among urban older women: Barriers, strategies and options. Journal of Transport Geography, 26, 166-174. https://doi.org/10.1016/j. jtrangeo.2012.10.003.

OECD. (2001). Ageing and transport. Paris: Organisation for Economic Cooperation and Development. 
Ohnmacht, T., Maksim, H., \& Bergman, M. M. (Eds.). (2009). Mobilities and inequality. Farnham: Ashgate Publishing.

Retière. (2003). Autour de l'autochtonie. Réflexions sur la notion de capital social populaire. Politix, 16(63), 121-143.

Risser, R., Haindl, G., \& Ståhl, A. (2010). Barriers to senior citizens' outdoor mobility in Europe. European Journal of Ageing, 7(2), 69-80. https://doi.org/10.1007/s10433-010-0146-4.

Sen, A. (1993). Capability and Well-being. In M. C. Nussbaum \& A. Sen (Eds.), The quality of life (pp. 30-53). Oxford: Oxford University Press.

SEU. (2003). Making the connections: Final report on transport and social exclusion. London: Social Exclusion Unit - Office of the Deputy Prime Minister.

Shergold, I., \& Parkhurst, G. (2012). Transport-related social exclusion amongst older people in rural Southwest England and Wales. Journal of Rural Studies, 28(4), 412-421. https://doi. org/10.1016/j.jrurstud.2012.01.010.

Swedish National Institute of Public. (2007). Healthy ageing: a challenge for Europe. Swedish National Institute of Public Health. http://www.healthyageing.eu/sites/www.healthyageing. eu/files/resources/Healthy\%20Ageing $\% 20-\% 20$ A $\% 20$ Challenge\%20for\%20Europe.pdf. Accessed 9 Oct 2019.

Urry, J. (2007). Mobilities. Cambridge: Polity Press.

Open Access This chapter is licensed under the terms of the Creative Commons Attribution 4.0 International License (http://creativecommons.org/licenses/by/4.0/), which permits use, sharing, adaptation, distribution and reproduction in any medium or format, as long as you give appropriate credit to the original author(s) and the source, provide a link to the Creative Commons license and indicate if changes were made.

The images or other third party material in this chapter are included in the chapter's Creative Commons license, unless indicated otherwise in a credit line to the material. If material is not included in the chapter's Creative Commons license and your intended use is not permitted by statutory regulation or exceeds the permitted use, you will need to obtain permission directly from the copyright holder.

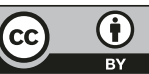

